\title{
Design, Synthesis, and Application of Colored Cobalt Pigments (Pink, Blue, Green)
}

\author{
Fauze J. Anaissi, ${ }^{\circledR *, a}$ Dienifer F. L. Horsth, ${ }^{a}$ Jaqueline Dalastra, ${ }^{a}$ Julia O. Primo, ${ }^{a}$ \\ Ketlyn W. Borth, ${ }^{a}$ Maria L. M. Rocha ${ }^{a}$ and Nayara Balaba ${ }^{a}$ \\ ${ }^{a}$ Departamento de Química, Universidade Estadual do Centro-Oeste (UNICENTRO), \\ 85040-080 Guarapuava-PR, Brazil
}

\begin{abstract}
The combination of white or colorless oxides $\left(\mathrm{MgO}, \mathrm{Al}_{2} \mathrm{O}_{3}, \mathrm{ZnO}\right)$ with colorant ions $\left(\mathrm{Co}^{2+}\right)$ generates colored pigments (pink, blue, green). The color is caused by the insertion of the colorant ion in the respective crystal lattices (periclase, alumina, wurtzite), as verified by X-ray diffraction. Absorption spectra in the visible region show analogous triplet behavior of the absorption bands for the doped alumina and wurtzite samples but a difference in tetrahedral distortion, which generates blue and green pigments. In contrast, cobalt-doped periclase has color-related parameters related to the pink color. Crystallite and particle sizes show nanometric dimensions in the range of 20-60 nm (magnesium), 20-180 nm (aluminum), and 40-220 nm (zinc). The color is related to the shape (crystalline phase), size, and presence of chromophore ions with absorption in the visible region. Colorimetric studies (CIE L*a*b*) show variations between colors as a function of the polysaccharide that is used (starch or pectin) as fuel. The color variation is subtle in some cases but is significantly noticeable in other cases. Commercial colorless ink dispersion $(10 \% \mathrm{~m} / \mathrm{m})$ shows excellent compatibility with the maintenance of hues and a slight increase in color saturation $\left(\mathrm{C}^{*}\right)$.
\end{abstract}

Keywords: polysaccharide, doping, cobalt, pigments, colorimetry

\section{Introduction}

Colors can be indicative of health and food types. ${ }^{1-3}$ Natural colors, organic or inorganic, have a permanent influence and play an important role in decision-making or in reviewing concepts. ${ }^{4,5}$

Colors are influential in decision-making when purchasing assets, such as houses and cars or consumables, such as food, beverages, and clothing. ${ }^{1-3}$ Each season or year, a predominant or trendy color is chosen. For example, in 2020, the color trend is Pantone Classic Blue 19-4052; a timeless and resistant tone. ${ }^{6}$

Color in substances is due to the presence of dyes or pigments, and have different sizes and shapes. ${ }^{7}$ Dyes are soluble in different media or substrates, while pigments are dispersed in the medium. ${ }^{4,5,8}$ Inorganic pigments (minerals) include compounds of different classes and chemical properties, such as metal oxides, sulfides, carbonates, chromates, sulfates, phosphates, and silicates. ${ }^{8,9}$

Synthetic inorganic pigment (SIP) manufacturing is a fast-growing industry that seeks to prepare new colors with excellent reproducibility, low toxicity, high purity, and

*e-mail: anaissi@unicentro.br

Tribute to Professor Henrique Eisi Toma on his $70^{\text {th }}$ birthday. transition metal as coloring ion. ${ }^{4-6,10,11}$ Thus, the design of new molecules, particles, clusters, or colored aggregates requires the development of versatile, inexpensive, easy to reproduce, and industrially scalable methodologies. ${ }^{7,11}$

Synthesis of inorganic pigments using polysaccharides as a coordinating template and as fuel is receiving attention from research groups and industry as a technically and economically viable alternative. ${ }^{1-12}$ Citrus pectin and cassava starch are polysaccharides that are rich in amylose and amylopectin (Figure 1). Amylose (CAS 9005-82-7) consists of glucose units joined by $\alpha-(1,4)$ glycosidic bonds, giving rise to a straight-chain with small branches. Amylopectin (CAS 9037-22-3) is formed by glucose units joined at $\alpha$-(1,4)-positions and has branching points at $\alpha$-(1,6)-positions, thus having a branched structure. ${ }^{11,13}$

Using state-of-the-art methods, we have prepared colored oxides for application as SIPs. ${ }^{10,11,14}$ In this study, we present the synthesis of pigments based on a cobalt colorant ion as a dopant of the colorless matrices of aluminum, magnesium, and zinc oxides. Doping leads to different colors as a function of the matrix. For comparison, we used citrus pectin gelation and colloidal starch suspension as coordinating agents and synthesis fuel. The pigments were characterized according to the phase formed by $\mathrm{X}$-ray diffraction (XRD), particle size (dynamic light 
(a)
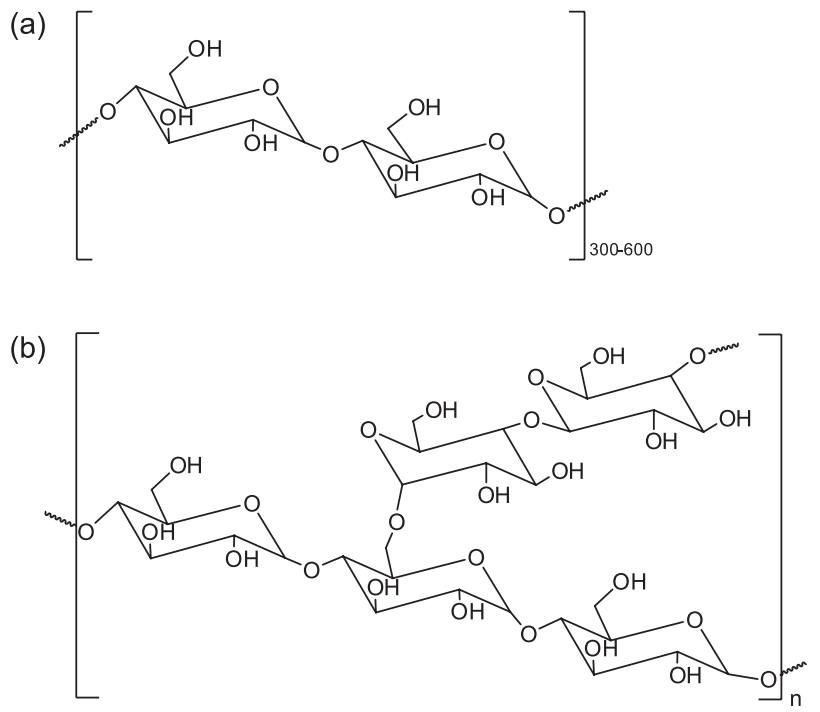

Figure 1. Structure of major polysaccharide constituents: (a) amylose and (b) amylopectin (adapted from reference 13).

scattering (DLS)), and electronic spectroscopic behavior (UV-Vis). A colorimetric study (Commission Internationale de l'Éclairage (CIE) L*a*b*) was performed to compare pigments in powder form and pigments dispersed in commercial colorless paint $(10 \% \mathrm{~m} / \mathrm{m})$. Results show point color chromaticity $\left(\mathrm{C}^{*}\right)$ being maintained, which indicates the possibility of commercial application.

\section{Experimental}

Reagents

Analytical grade reactants without any previous treatment were used for pigment synthesis. The inorganic salts used were as follows: aluminum nitrate nonahydrate $\left(\mathrm{Al}_{2}\left(\mathrm{NO}_{3}\right)_{3} \cdot 9 \mathrm{H}_{2} \mathrm{O}\right.$, P.A., Dinâmica, Indaiatuba, SP, Brazil); magnesium nitrate hexahydrate $\left(\mathrm{Mg}\left(\mathrm{NO}_{3}\right)_{2} \cdot 6 \mathrm{H}_{2} \mathrm{O}\right.$, P.A., Neon, Suzano, SP, Brazil); zinc nitrate hexahydrate $\left(\mathrm{Zn}\left(\mathrm{NO}_{3}\right)_{2} \cdot 6 \mathrm{H}_{2} \mathrm{O}, 98 \%\right.$, Dinâmica, Indaiatuba, SP, Brazil); and cobalt(II) nitrate hexahydrate $\left(\mathrm{Co}\left(\mathrm{NO}_{3}\right)_{2} \cdot 6 \mathrm{H}_{2} \mathrm{O}, 98 \%\right.$, Dinâmica, Indaiatuba, SP, Brazil). Natural cassava starch in the form of colloidal suspension and practical grade (P.A.) gelled citrus pectin was used as fuel sources in the combustion process. All solutions were prepared with distilled water.

\section{Pigment synthesis}

Colored pigments were prepared using two distinct methodologies: colloidal starch solution (CSS), ${ }^{11}$ and gelled citrus pectin (GCP) ${ }^{10,14}$ The methods differ not only in the sources of the polysaccharides, but also in that controlled heating $\left(80^{\circ} \mathrm{C}\right)$ is used for pectin gelation, whereas CSS starch extraction occurs at room temperature.
Colloidal starch solution (CSS) method

Starch (Figure 2a) was extracted from sago (cassava starch) and distilled water $(1: 5 \mathrm{~m} / \mathrm{m})$, and the suspension was mechanically stirred for a period of $4 \mathrm{~h}$ at room temperature. It was then sieved, and the colloidal starch was used as the base solution (CSS) to form a white matrix. In the white matrix obtained from CSS, the fraction of $2 \%(\mathrm{~m} / \mathrm{m})$ of base metal nitrate $(\mathrm{Mg} ; \mathrm{Al} ; \mathrm{Zn})$ is added. The colored pigments were prepared by adding cobalt(II) colorant ions at a ratio of 10 and $20 \%(\mathrm{~m} / \mathrm{m})$ relative to the white matrix containing the base metal ion. After $60 \mathrm{~min}$ of mechanical stirring at $600 \mathrm{rpm}$ at room temperature, the suspensions were calcined in a muffle furnace at a temperature of $1000{ }^{\circ} \mathrm{C}$ with a heating ramp of $10^{\circ} \mathrm{C} \mathrm{min}^{-1}$. The obtained solids were macerated in an agate mortar and sieved through a $250 \mathrm{~mm}$ (60 mesh) sieve.

\section{Gelled citrus pectin (GCP) method}

In this method (Figure $2 \mathrm{~d}$ ), citric pectin $(2 \% \mathrm{~m} / \mathrm{m})$ was added in preheated water $\left(80^{\circ} \mathrm{C}\right)$. After solubilization of pectin occurred, base metal nitrate $(\mathrm{Mg} ; \mathrm{Al} ; \mathrm{Zn})$ was added at a proportion of $2 \%(\mathrm{~m} / \mathrm{m})$ to obtain the respective white matrix. The process for obtaining colored pigments using the CSS method was followed. The synthesis pathways are presented in Figure 2.

\section{Characterization techniques}

The crystalline phases of the powders were examined on a model D2 Phase X-ray diffractometer (XRD, Bruker), using $\mathrm{Cu} \mathrm{K} \alpha$ radiation $(\lambda=1.5418 \AA$ ), with scanning in $2 \theta$ from 20 to $70^{\circ}$ and a step rate of $0.05^{\circ} \mathrm{s}^{-1}$. The phases were identified using Match!3 software ${ }^{15}$ and crystallographic files from the International Crystal Structure Database (ICSD). The average crystallite size (D) was determined using the Scherrer formula: ${ }^{16}$

$\mathrm{D}=\mathrm{k} \lambda / \beta \cos \theta$

where $\mathrm{k}=0.9$ and 1.3 (shape factor), $\lambda$ is the wavelength of $\mathrm{Cu} \mathrm{K} \alpha, \theta$ is the Bragg diffraction angle, and $\beta$ is the revised half-width of the most intense peak of the diffractogram in radian.

Particle size (DLS) was obtained by photon correlation spectroscopy at $25{ }^{\circ} \mathrm{C}$ using PCS Malvern Zetasizer Nanoseries ${ }^{\circledast}$ model ZS90. The samples were dispersed in $1.0 \mathrm{mg} \mathrm{mL} \mathrm{mL}^{-1}$ propylene glycol. The absorption spectra of the powdered pigments were measured in the range of 350-720 nm with a UV-Vis Ocean Optics 


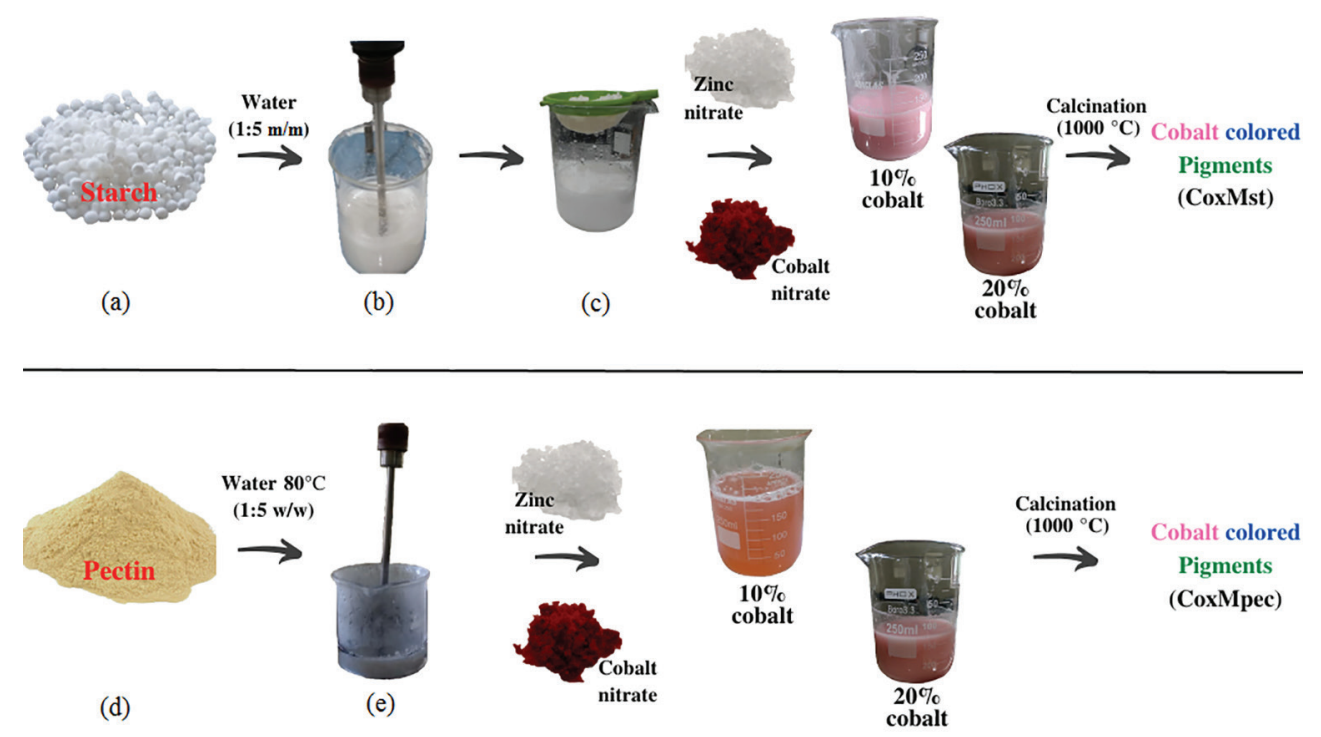

Figure 2. Procedure used to prepare the pigments with (top) colloidal starch solution (CSS) method ((a) water dispersion; (b) mechanical extraction; (c) sieving); and (bottom) gelled citric pectin (GCP) method ((d) hot water dispersion; (e) gelation) (adapted from references 10,11,14).

spectrophotometer (model USB 2000) with a tungstenhalogen lamp, and silicon (350-720 nm) and germanium $(720-1050 \mathrm{~nm})$ detectors.

\section{Dispersion in colorless paint and colorimetry}

The pigments were dispersed in a proportion of $10 \%(\mathrm{~m} / \mathrm{m})$ in water-based commercial colorless paint (Figure 3). Gypsum-based ceramic material specimens were painted with colorless pigmented paint. The pigment color in the powder form and painted specimens were evaluated by colorimetry. The colorimetric values were determined using a portable colorimeter (CR-400/410 Chroma Meter, Konica Minolta) with a D65 light source with a $2^{\circ}$ angle. The CIE $1976 \mathrm{~L} * \mathrm{a} * \mathrm{~b} *$ colorimetric method was used, as recommended by the CIE. ${ }^{17}$ According to the color coordinate system, $\mathrm{L}^{*}$ is lightness $\left(\mathrm{L}^{*}=0\right.$ for black and $\mathrm{L}^{*}=100$ for white), $\mathrm{a}^{*}$ is the green $(-)$ to red $(+)$ axis, and $b^{*}$ is the blue (-) to yellow (+) axis. The parameter $\mathrm{C}^{*}$ (chroma) represents color saturation and is defined as $(\mathrm{C} *)^{2}=\left[\left(\mathrm{a}^{*}\right)^{2}+(\mathrm{b} *)^{2}\right]{ }^{18}$

\section{Results and Discussion}

\section{Structural identification and particle size}

The identification of undoped and doped oxides is summarized in Table 1, and considers the following methodology for white pigments: $\mathrm{M}_{\mathrm{st}}$ and $\mathrm{M}_{\mathrm{pec}}$; and colored pigments: $\mathrm{Co}_{\mathrm{x}} \mathrm{M}_{\mathrm{st}}$ and $\mathrm{Co}_{\mathrm{x}} \mathrm{M}_{\text {pec }}$; where $\mathrm{M}=\mathrm{Mg}$, $\mathrm{Al}$, or $\mathrm{Zn}$; $\mathrm{x}=10$ and $20 \%$ of dopant; and "st" for pigments obtained with starch (CSS) and "pec" for those obtained with pectin

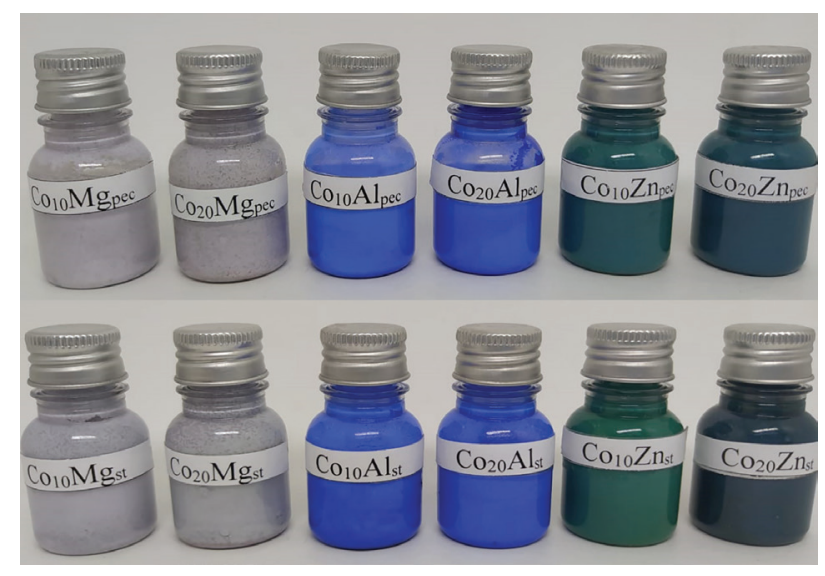

Figure 3. Photographs of Co-doping pigments in different host matrices $\left(\mathrm{MgO}, \mathrm{Al}_{2} \mathrm{O}_{3}\right.$, and $\left.\mathrm{ZnO}\right)$ and different dopant concentrations.

(GPC). The white and colored pigments were identified by $\mathrm{X}$-ray diffractometry (Figure 4), and the data are presented in Table 1.

The main crystalline phase identified for the magnesium samples (Figure 4a) was periclase (MgO, ICSD: 9863) for both synthesis methods adopted. The typical single-phase formation of pure magnesium oxides produced at high temperatures indicates that cobalt ions replace magnesium ions without altering the periclase crystal structure. ${ }^{19-21}$ This is due to the similarity in the ionic radius of both metals $\left(\mathrm{Mg}^{2+}=0.72 \AA ; \mathrm{Co}^{2+}=0.75 \AA\right.$ 和 $\left.o^{3+}=0.61 \AA\right)$. The structure of the periclase does not effectively indicate the substitution of $\mathrm{Mg}$ by $\mathrm{Co}$. An additional peak detected at $38.7^{\circ}$ is consistent with the NaF phase (ICSD: 52238), which is possibly been generated in trace amounts by impurities in the magnesium salt. ${ }^{20}$ 
Table 1. Crystallinity degree, crystallite size, and particle size of colored cobalt pigments

\begin{tabular}{|c|c|c|c|c|}
\hline \multirow{2}{*}{ Sample } & \multirow{2}{*}{ Crystallinity / \% } & \multicolumn{2}{|c|}{ Crystallite size / nm } & \multirow{2}{*}{$\begin{array}{c}\text { Particle } \\
\text { size / } \mathrm{nm}\end{array}$} \\
\hline & & $\mathrm{k}=0.9$ & $\mathrm{k}=1.3$ & \\
\hline $\mathrm{Mg}_{\mathrm{st}}$ & 87.8 & 19.2 & 27.7 & 46.99 \\
\hline $\mathrm{Co}_{10} \mathrm{Mg}_{\mathrm{st}}$ & 88.6 & 32.1 & 46.3 & 77.15 \\
\hline $\mathrm{Co}_{20} \mathrm{Mg}_{\mathrm{st}}$ & 85.8 & 40.5 & 58.5 & 50.42 \\
\hline $\mathrm{Mg}_{\mathrm{pec}}$ & 92.2 & 30.5 & 44.1 & 44.78 \\
\hline $\mathrm{Co}_{10} \mathrm{Mg}_{\text {pec }}$ & 87.9 & 34.0 & 49.1 & 34.71 \\
\hline $\mathrm{Co}_{20} \mathrm{Mg}_{\mathrm{pec}}$ & 86.8 & 42.2 & 61.0 & 56.79 \\
\hline $\mathrm{Al}_{\mathrm{st}}$ & 52.7 & 57.8 & 83.5 & 27.99 \\
\hline $\mathrm{Co}_{10} \mathrm{Al}_{\mathrm{st}}$ & 63.5 & 14.3 & 20.7 & 28.93 \\
\hline $\mathrm{Co}_{20} \mathrm{Al}_{\mathrm{st}}$ & 61.1 & 17.6 & 25.4 & 187.50 \\
\hline $\mathrm{Al}_{\mathrm{pec}}$ & 54.7 & 41.7 & 60.2 & 97.47 \\
\hline $\mathrm{Co}_{10} \mathrm{Al}_{\mathrm{pec}}$ & 52.6 & 10.5 & 15.1 & 27.85 \\
\hline $\mathrm{Co}_{20} \mathrm{Al}_{\mathrm{pec}}$ & 56.5 & 20.0 & 28.8 & 131.60 \\
\hline $\mathrm{Zn}_{\mathrm{st}}$ & 91.6 & 52.6 & 76.0 & 85.69 \\
\hline $\mathrm{Co}_{10} \mathrm{Zn}_{\mathrm{st}}$ & 76.4 & 43.0 & 62.0 & 158.13 \\
\hline $\mathrm{Co}_{20} \mathrm{Zn}_{\mathrm{st}}$ & 62.9 & 47.3 & 68.3 & 197.90 \\
\hline $\mathrm{Zn}_{\mathrm{pec}}$ & 91.6 & 49.6 & 71.7 & 82.21 \\
\hline $\mathrm{Co}_{10} \mathrm{Zn}_{\mathrm{pec}}$ & 73.6 & 44.4 & 64.2 & 109.30 \\
\hline $\mathrm{Co}_{20} \mathrm{Zn}_{\mathrm{pec}}$ & 69.7 & 54.7 & 79.0 & 227.40 \\
\hline
\end{tabular}

$\mathrm{k}$ : shape factor.

The undoped and doped aluminum oxides exhibited different behaviors (Figure 4b); X-ray diffraction profiles changed according to the synthesis methodology used (CSS or GCP) and the presence of Co doping ions. Comparing the standards of the ICSD database, the formation of three polymorphs of alumina, alpha (ICSD: 20856), gamma (ICSD: 99836) and kappa (ICSD: 94485), has been confirmed. A higher predominance of the $\gamma$-alumina polymorph for oxides was obtained via the CSS method, whereas the $\alpha$-alumina was predominantly formed by the GCP method. The alpha phase is thermodynamically more stable, but its formation involves several polymorphic transformations and is highly dependent on the energy of the reaction medium. ${ }^{22}$ This means that the predominance of the $\alpha$-alumina phase when using pectin suggests that there is a greater release of thermal energy from this polysaccharide than from starch. The presence of cobalt ions in the oxide structure hinders the polymorphic transition (since $\gamma$-alumina is generated at $\left.1000{ }^{\circ} \mathrm{C}\right)$ and cobalt aluminate $\left(\mathrm{CoAl}_{2} \mathrm{O}_{4}\right.$, ICSD: 260589), thus, the blue pigment is generated. The formation of a secondary phase, blue cobalt aluminate, has been reported in the literature, ${ }^{23,24}$ and is related to the structural deformation due to the insertion of an ion with a larger ionic radius than aluminum $(0.53 \AA)$.

Figure $4 \mathrm{c}$ shows the $\mathrm{X}$-ray diffraction profile of undoped zinc oxide and doped with cobalt (green pigments; Rinmann green). ${ }^{25}$ The main indexed peaks refer to the Miller indices [(100), (002), and (101)], and coincide with the wurtzite hexagonal phase (ICSD: 154486). Previous results ${ }^{11,26,27}$ showed the predominant monophasic formation of wurtzite for cobalt-doped zinc oxide, which confirmed the isomorphic substitution of cobalt ions into the crystalline zinc structure. However, it is noted that for the $\mathrm{Co}_{20} \mathrm{Zn}_{\mathrm{st}}$ sample obtained by the CSS method, there is a low-intensity peak at $36.8^{\circ}$ attributed to $\mathrm{ZnCo}_{2} \mathrm{O}_{4}$ (ICSD: 73755), similar to that found for the blue pigment. In other words, the starch does not provide as much energy as pectin, and therefore the solubility of cobalt and the organization of atoms in the crystal lattice decreases, which does not stabilize a single phase (wurtzite). ${ }^{26}$

Using the X-ray diffractograms, it was possible to calculate the average size of the crystallite using
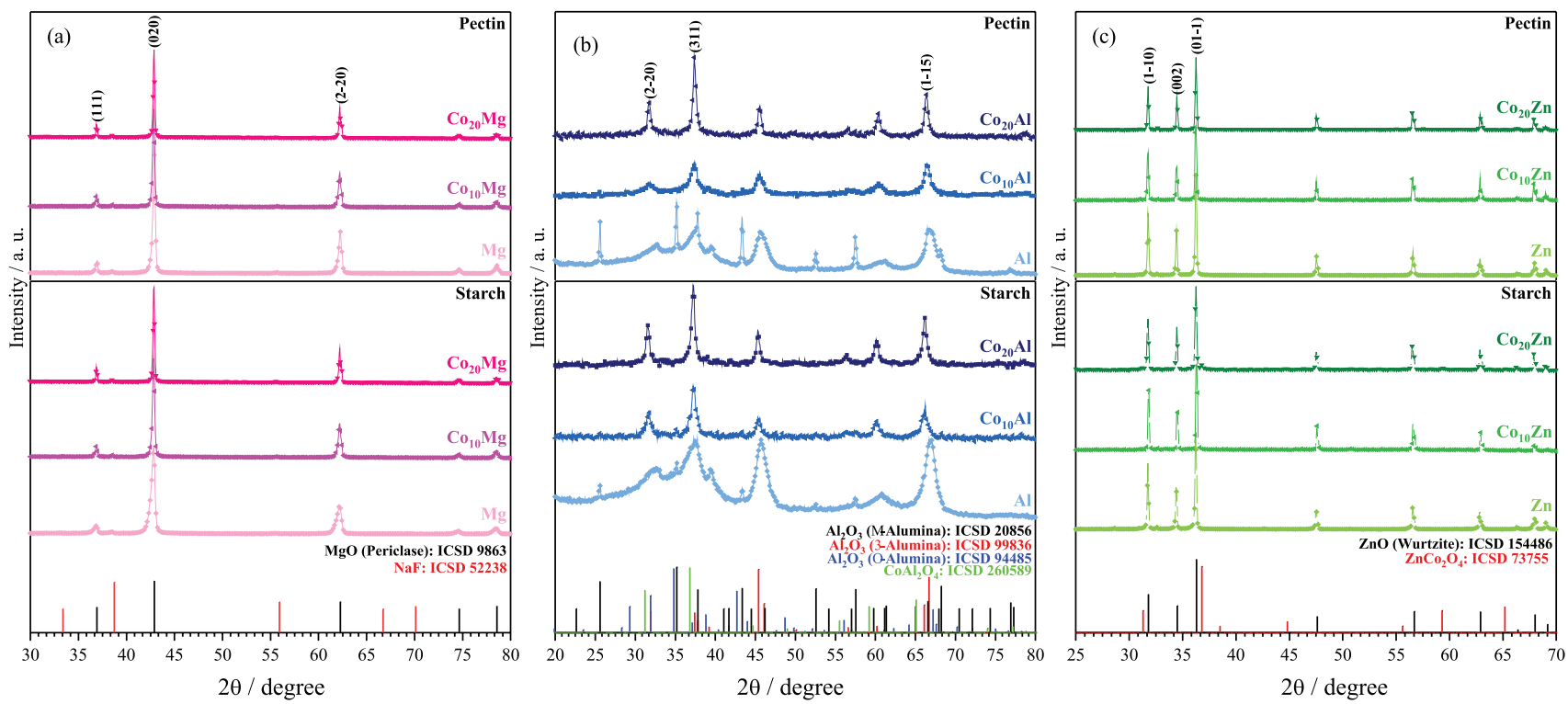

Figure 4. X-ray diffraction patterns of the pigments prepared to incorporate cobalt ions in oxide matrices of (a) magnesium; (b) aluminum; (c) zinc. 
Scherrer's equation. ${ }^{16}$ The crystallite size and percentage of crystallinity values are shown in Table 1. Considering the values of the shape factor, $\mathrm{k}$, and the degree of crystallinity of the oxides, the size of the crystallite is directly related to the intensity and width of the peak, and varies according to the crystalline structure of the oxide matrices. The diffraction peak is modified by factors such as structural defects and crystal lattice stress, and both are considered when doping a crystalline system. ${ }^{28}$ Particle size data (DLS) show this trend (Table 1); the addition of the colorant ion in the oxide matrices does not reflect a linear behavior. The smallest particle sizes were observed for $10 \%$ cobalt iondoped aluminum samples $\left(\mathrm{Co}_{10} \mathrm{Al}_{\text {pec }}, 27.85 \mathrm{~nm} ; \mathrm{Co}_{10} \mathrm{Al}_{\mathrm{st}}\right.$, $27.99 \mathrm{~nm}$ ). The largest particle size values were found for $20 \%$ cobalt ion-doped zinc oxide $\left(\mathrm{Co}_{20} \mathrm{Zn}_{\mathrm{pec}}, 227.40 \mathrm{~nm}\right.$; $\left.\mathrm{Co}_{20} \mathrm{Zn}_{\mathrm{st}}, 197.90 \mathrm{~nm}\right)$. The discrepancy between DLS and crystallite size (XRD) may be dependent on the method used for sample dispersion, i.e., the suspension of $1.0 \mathrm{mg} \mathrm{mL}^{-1}$ in propylene glycol.

\section{Visible spectroscopy}

Figure 5 shows the visible region of the electronic spectra obtained in diffuse reflectance mode for cobalt pigments in powder form. Initially, we highlight that all matrices $(\mathrm{Mg}, \mathrm{Al}$ and $\mathrm{Zn})$ are white, as they do not have absorption bands in the visible spectrum region (Figure 5). This is shown for comparison purposes with their respective pigments.

Doped magnesium oxide pigments (Figure 5a) have a broadband between $475-575 \mathrm{~nm}$, with maximum absorption at $515 \mathrm{~nm}$, regardless of the polysaccharide used (starch or pectin). This band is assigned to the ${ }^{4} \mathrm{~A}_{2}(\mathrm{~F}) \rightarrow{ }^{4} \mathrm{~T}_{1}(\mathrm{P})$ transition of cobalt(II) in a tetrahedral arrangement. ${ }^{29,30}$ The intensity of the band increases due to the increase in $\mathrm{Co}^{\text {II }}$ doping, which suggests the effect of isomorphic $\mathrm{Mg}^{2+}$ substitution by $\mathrm{Co}^{2+}$ ions in the crystal lattice. ${ }^{31}$

Figure $5 \mathrm{~b}$ shows the electronic spectra of the aluminates. Similarly, independent of the polysaccharides utilized, there is a triplet of absorption bands $(545,585$, and $635 \mathrm{~nm})$ that can be attributed to the ${ }^{4} \mathrm{~A}_{2}(\mathrm{~F}) \rightarrow{ }^{4} \mathrm{~T}_{1}(\mathrm{P})$ transition. This is allowed by spin in the Jahn-Teller distorted tetrahedral structures of the $\mathrm{Co}^{2+}$ ion, and results in the blue coloration of the pigments. ${ }^{32}$

The absorption spectra for samples containing zinc (Figure 5c) after cobalt doping highlight the presence of a triplet of bands $(570,615$, and $665 \mathrm{~nm})$, which is characteristic of the d-d transitions of $\mathrm{Co}^{2+}$ ions. In a tetrahedral environment, the ${ }^{4} \mathrm{~A}_{2}(\mathrm{~F}) \rightarrow{ }^{4} \mathrm{~T}_{1}(\mathrm{P})$ transition was attributed to the substitution of $\mathrm{Zn}^{2+}$ ions for $\mathrm{Co}^{2+}$ (a)
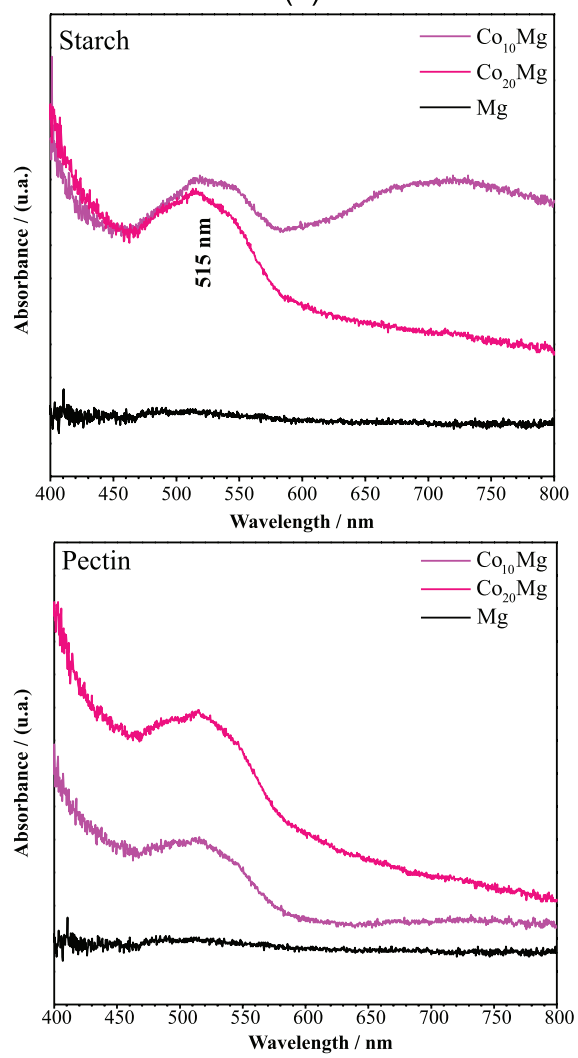

(b)
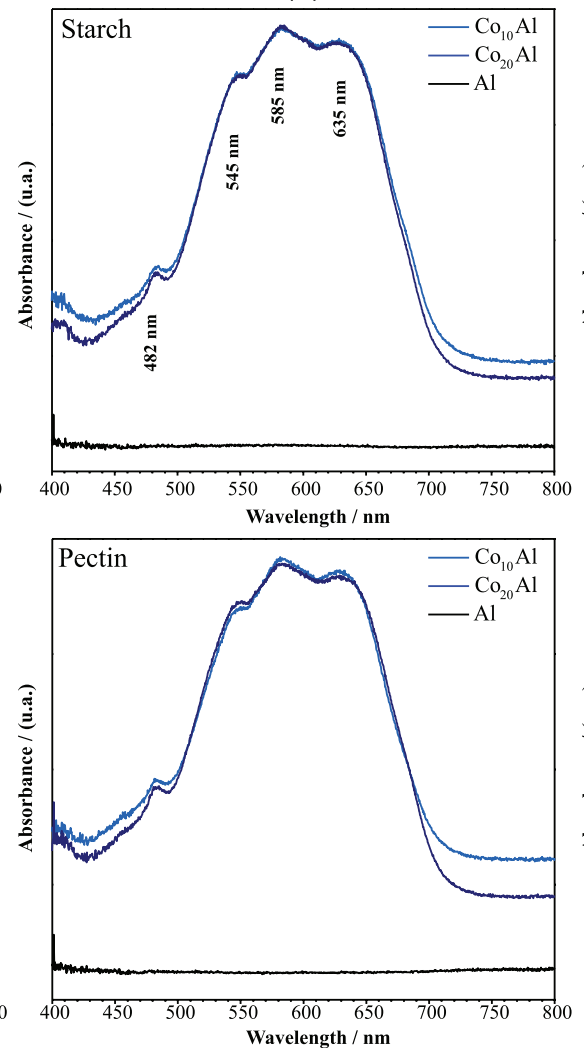

(c)
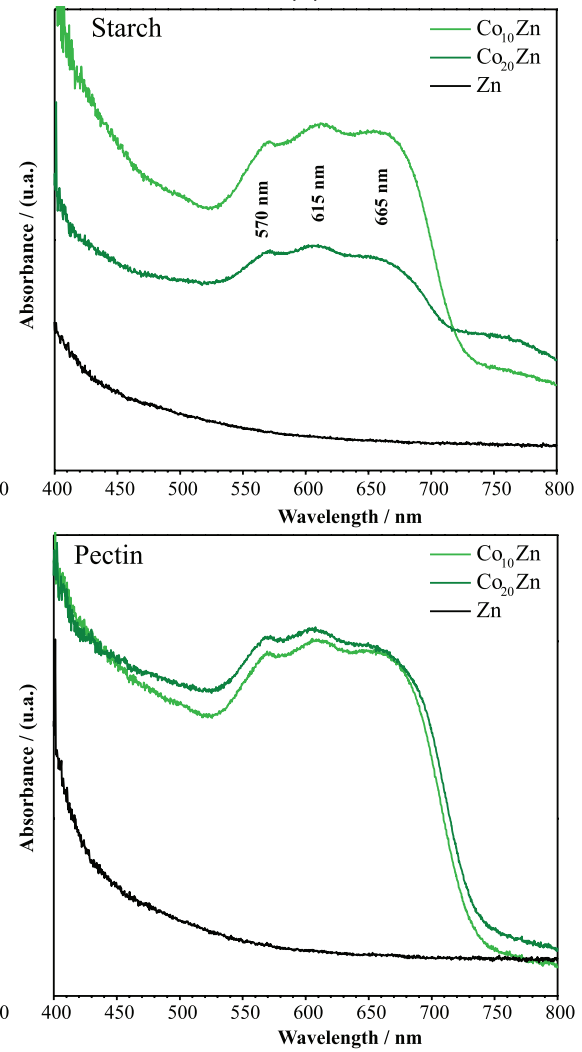

Figure 5. Visible absorption spectra of synthesized pigments prepared to incorporate cobalt ions in oxide matrices of (a) magnesium; (b) aluminum; (c) zinc. 
ions in the tetrahedral structure. ${ }^{11,33}$ The offset of the triplet band position with band flattening compared to Co-doped aluminum spectra (Figure $5 b$ ) is due to the difference in host matrix structures ( $\mathrm{Zn}$ and $\mathrm{Al}$ ). This results in the color variation of the pigments, with a greater red shift in the zinc samples, generating green pigments. ${ }^{27}$

\section{Colorimetric study}

The coloration of pigments obtained in different synthesis and dopant matrices was evaluated by CIE L*a*b*, 1976. ${ }^{17}$ The values of the colorimetric parameters and the calculated values of $\Delta \mathrm{E}$ and $\mathrm{C}^{*}$ are listed in Table 2 . According to

Table 2. Colorimetric parameters (CIE L*a*b*) for pigments in dry powder form

\begin{tabular}{|c|c|c|c|c|c|c|}
\hline Sample & Sample figure & $\mathrm{L}^{*}$ & $a^{*}$ & $\mathrm{~b}^{*}$ & $\mathrm{C}^{*}$ & $\Delta \mathrm{E}$ \\
\hline $\mathrm{Co}_{10} \mathrm{Mg}_{\mathrm{pec}}$ & & 77.59 & 4.24 & 8.36 & 9.37 & \\
\hline $\mathrm{Co}_{10} \mathrm{Mg}_{\mathrm{st}}$ & & 75.94 & 2.68 & 6.21 & 6.76 & \\
\hline $\mathrm{Co}_{20} \mathrm{Mg}_{\mathrm{pec}}$ & & 79.50 & 7.01 & 9.35 & 11.68 & \\
\hline $\mathrm{Co}_{20} \mathrm{Mg}_{\mathrm{st}}$ & & 73.75 & 6.34 & 6.88 & 16.90 & \\
\hline $\mathrm{Co}_{10} \mathrm{Al}_{\text {pec }}$ & & 44.15 & 18.83 & -45.58 & 49.31 & \\
\hline $\mathrm{Co}_{10} \mathrm{Al}_{\mathrm{st}}$ & & 36.82 & 23.57 & -49.82 & 55.09 & \\
\hline $\mathrm{Co}_{20} \mathrm{Al}_{\mathrm{pec}}$ & & 35.28 & 27.99 & -54.04 & 60.85 & \\
\hline $\mathrm{Co}_{20} \mathrm{Al}_{\mathrm{st}}$ & & 36.73 & 29.53 & -56.42 & 63.68 & \\
\hline $\mathrm{Co}_{10} \mathrm{Zn}_{\mathrm{pec}}$ & & 34.77 & -16.19 & 1.59 & 16.27 & \\
\hline $\mathrm{Co}_{10} \mathrm{Zn}_{\mathrm{st}}$ & & 41.35 & -20.89 & 2.36 & 21.02 & \\
\hline $\mathrm{Co}_{20} \mathrm{Zn}_{\mathrm{pec}}$ & & 28.77 & -11.77 & 0.24 & 11.77 & \\
\hline $\mathrm{Co}_{20} \mathrm{Zn}_{\mathrm{st}}$ & & 28.72 & -10.17 & 0.08 & 10.17 & \\
\hline
\end{tabular}

$\mathrm{L}^{*}$ : lightness; $\mathrm{a}^{*}$ : green (-) to red (+) axis; $\mathrm{b}^{*}$ : blue (-) to yellow (+) axis; $\mathrm{C}^{*}$ : color saturation; $\Delta \mathrm{E}$ : color difference. 
colorimetric data $\left(\mathrm{L}^{*} \mathrm{a} * \mathrm{~b} *\right)$, Co-doping in different host matrices results in pigments with different colorations. Co-doped magnesium samples are pink in color, and their colorimetric parameters are located in the red/yellow quadrant, whose values are $\mathrm{a}^{*}(+)$ and $\mathrm{b}^{*}(+)$. Co-doped aluminum pigments exhibit blue coloration, that is, they presented $\mathrm{b}^{*}(-)$ values, which are positioned in the red/blue quadrant. For Co-doped zinc pigments, parameters a* $(-)$ and $b^{*}(+)$ were obtained, and are located in the green/ yellow quadrant, thus denoting their green coloration.

The highest luminosity $\left(\mathrm{L}^{*}\right)$ was obtained for Co-doped magnesium pigments $\left(\mathrm{L}^{*}>70\right)$, while Co-doped aluminum presented higher saturation values $\left(C^{*}>40\right)$. The zinc sample with $20 \%$ colorant ion presented the lowest value of $\Delta \mathrm{E}$, that is a visual perception of the color difference is not possible. While aluminum samples containing $10 \%$ of the colorant ion have the highest $\Delta \mathrm{E}$ value, the color perception difference is strong, or quite distinct. ${ }^{3}$

Application of pigments in colorless paint

Table 3 shows the CIE $1976^{17}$ color coordinate values of

Table 3. Colorimetric parameters (CIE $L * a * b *)$ for pigment dispersion in colorless paint

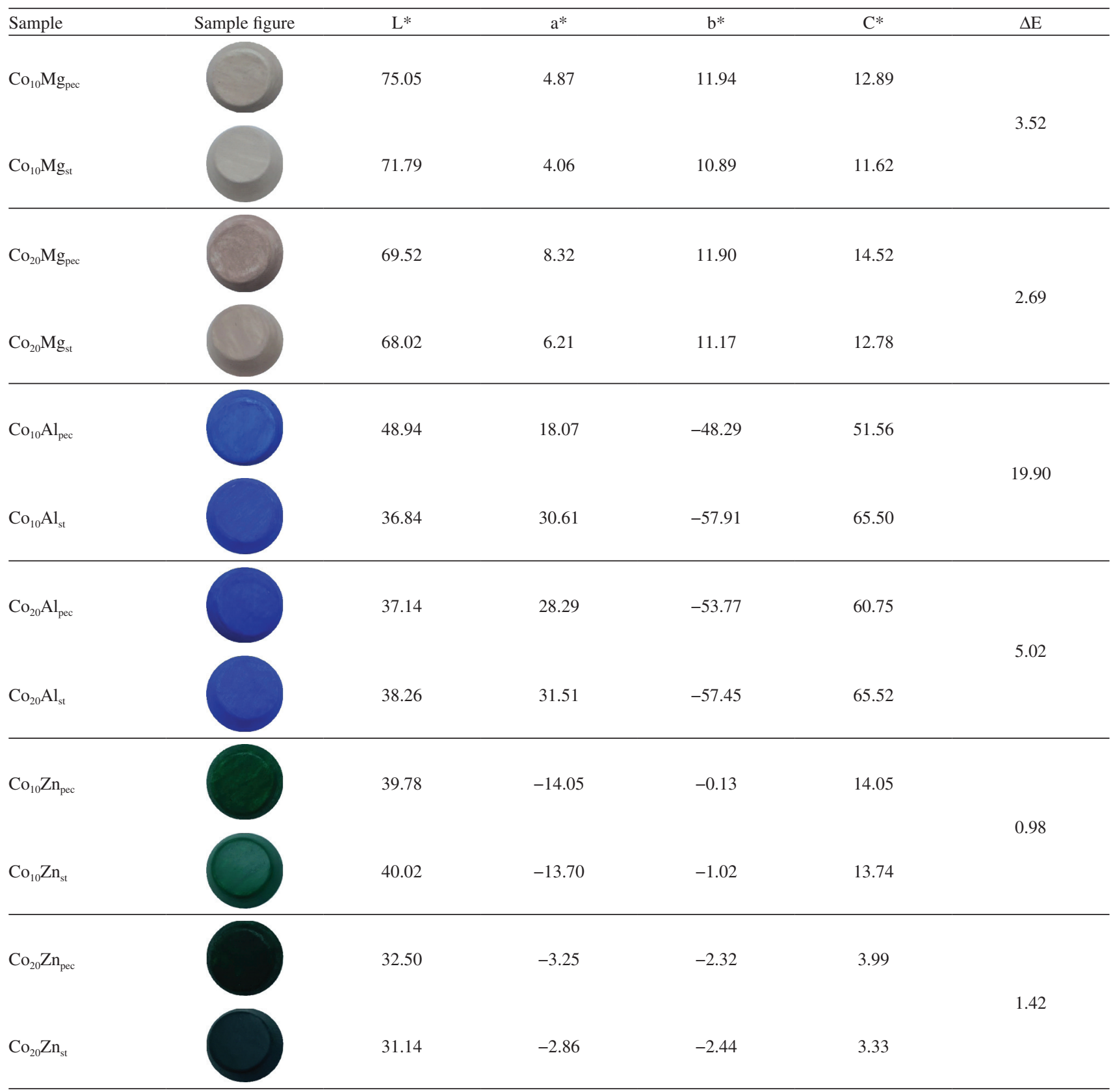

$\mathrm{L}^{*}$ : lightness; $\mathrm{a}^{*}$ : green (-) to red (+) axis; $\mathrm{b}^{*}$ : blue (-) to yellow (+) axis; $\mathrm{C}^{*}$ : color saturation; $\Delta \mathrm{E}$ : color difference. 
pigments dispersed in colorless paint, presenting different values of the colorimetric coordinates when comparing the powder samples, due to their form and degree of dispersion in the paint. Green pigments (Co-doped zinc) when dispersed in paint change the color quadrant of the samples to green/blue, with parameters $\mathrm{a}^{*}(-)$ and b* (-), expressing secondary color behavior. Co-doped magnesium and zinc samples dispersed in paint have low values of $\Delta \mathrm{E}$, indicating that when pigments are obtained by different methods, they have a little perceptual color difference. However, for Co-doped aluminum pigments, the color difference $(\Delta \mathrm{E})$ increased, indicating a stronger difference for $10 \%$ Co-doped, and clear difference for $20 \%$ Co-doped pigments.

\section{Conclusions}

Cobalt colored pigments were prepared by doping white oxides $\left(\mathrm{MgO}, \mathrm{Al}_{2} \mathrm{O}_{3}, \mathrm{ZnO}\right)$ with $\mathrm{Co}^{2+}$ colorant ion as coordinating agents and as a synthesis fuel; colloidal starch (CSS method) and gelled pectin (GCP method) were used. The coloring ion maintained the crystalline structure of the respective oxides (periclase, alumina, and wurtzite), imparting to them pink, blue, and green color. The coloration is directly related to the replacement of metal ions in their crystalline structures, which distorts the predominantly tetrahedral geometry. The absorption spectrum in the visible region for $\mathrm{CoMg}$ pigments has a broad band (475-575 nm) with maximum absorption at $515 \mathrm{~nm}$, which is typical of a d-d transition. A broad triplet absorption band is formed for the CoAl $(500-675 \mathrm{~nm})$ and CoZn $(550-725 \mathrm{~nm})$ pigments, which is typical of JahnTeller distorted tetrahedral structures, and results in blue and green colors, respectively. Colorimetric studies show the color similarity between the samples prepared by the two synthesis methods, and when dispersed in colorless paint, their hues are maintained with inconspicuous variations. Colors are related to the crystalline structure, size, composition, and presence of $\mathrm{Co}^{2+}$ colorant ions.

\section{Acknowledgments}

The authors thank the funding agencies: $\mathrm{CNPq}$ (310041/2016-3 and 427127/2018-1), CAPES, Finep, and Fundação Araucária (001/2016, CPBA/PROPESP). The co-authors thank CAPES for their master's (D. F. L. H., K. W. B., M. L. M. R., and N. B.) and doctoral (J. O. P.) scholarships. J. D. thanks CNPq for her PIBIC scholarship. This article is a tribute to Professor Henrique Eisi Toma on his $70^{\text {th }}$ birthday.

\section{Author Contributions}

The manuscript was collectively prepared by undergraduate and graduate students guided by the corresponding author (Fauze J. Anaissi). In alphabetical order they had the following contribution: Dienifer F. L. Horsth: obtaining and discussing the absorption spectra in the visible region; Jaqueline Dalastra: dispersion of pigments in colorless paint and preparation of painted specimens; Julia O. Primo: discussing colorimetric data; Ketlyn W. Borth: preparing X-ray diffraction samples, identifying and discussing XRD; Maria L. M. Rocha: dispersion of propylene glycol pigments and obtaining particle size data (DLS); and Nayara Balaba: responsible for pigment synthesis, spraying, and identification.

\section{References}

1. Csillag, P.; Comunicação em Cores. Uma Abordagem Científica pela Percepção Visual; SENAI: São Paulo, 2015.

2. https://segredosdomundo.r7.com/cores-significados-tipos-einfluencia-das-cores-no-cerebro-humano/, accessed in April 2020.

3. Quindici, M.; O Segredo das Cores; All Print Editora: São Paulo, 2013.

4. Buxbaum, G.; Industrial Inorganic Pigments; Wiley VCH: Lincoln, United Kingdom, 1998.

5. Borth, K. W.; Ferreira, R.; Valenga, M. G. P.; Galante, D.; Anaissi, F. J.; S. Afr. J. Chem. 2019, 72, 215.

6. https://www.pantone.com.br/inteligencia-da-cor/cor-do-ano2020-classic-blue/, accessed in April 2020.

7. Toma, H. E.; Bonifácio, L. S.; Anaissi, F. J.; Quim. Nova 2005 , $28,897$.

8. Veloso, L. A.; Dossie Técnico: Corantes e Pigmentos; Instituto de Tecnologia do Paraná - Tecpar: Curitiba, 2012. Available at http://www.respostatecnica.org.br/dossie-tecnico/ downloadsDT/NTcwOA==, accessed in April 2020.

9. Pereira, A. R. P.; Silva, M. J. S. F.; Oliveira, J. A. S.; Ceramica 2007, 53, 35 .

10. Dalpasquale, M.; Mariani, F. Q.; Müller, M.; Anaissi, F. J.; Dyes Pigm. 2016, 125, 124.

11. Primo, J. O.; Borth, K. W.; Peron, D. C.; Teixeira, V. C.; Galante, D.; Bittencourt, C.; Anaissi, F. J.; J. Alloys Compd. 2019, 780, 17.

12. Denardin, C. C.; Silva, L. P.; Cienc. Rural 2009, 39, 945.

13. Storpirtis, S.; Rev. Bras. Cienc. Farm. 2006, 42, 615.

14. Mariani, F. Q.; Borth, K. W.; Muller, M.; Dalpasquale, M.; Anaissi, F. J.; Dyes Pigm. 2017, 137, 403.

15. Match! Personal Licence, version 3.10.1; Crystal Impact GbR, Germany, 2019.

16. Scherrer, P.; Nachr. Ges. Wiss. Goettingen, Math.-Phys. Kl. 1918, 1918, 98. 
17. Commission Internationale de l'Éclairage (CIE); Recommendations on Uniform Colour Spaces, Colour Difference Equations, Psychometrics Colour Terms, Supplement No. 2 to Publication CIE No. 715 (E1-131) 1971; Bureau Central de la CIE: Paris, 1978.

18. Bao, W.; Ma, F.; Zhang, Y.; Hao, X.; Deng, Z.; Zou, X.; Gao, W.; Powder Technol. 2016, $292,7$.

19. Cullity, B. D.; Stock, S. R.; Elements of X-Ray Diffraction; $3^{\text {rd }}$ ed.; Addison-Wesley Publishing Company: Boston, Massachusetts, 1956.

20. Heredia, A. C.; Oliva, M. I.; Agñ, B.; Zandalazini, C. I.; Marchetti, S. G.; Herrero, E. R.; Crivello, M. E.; J. Magn. Magn. Mater. 2013, 342, 38.

21. Alvarado, E.; Torres-Martinez, L. M.; Fuentes, A. F.; Quintana, P.; Polyhedron 2000, 19, 2345.

22. Salem, R. E. P.; Chinelatto, A. S. A.; Chinelatto, A. L.; Ceramica 2014, 60, 108.

23. Reynoso, A. J.; Ayastuy, J. L.; Iriarte-Velasco, U.; GutiérrezOrtiz, M. A.; Appl. Catal., B 2018, 239, 86.

24. Dalpasquale, M.; Andrade, T. M.; Parabocz, C. R. B.; Anaissi, F. J.; Orbital: Electron. J. Chem. 2018, 10, 191.
25. Patra, M. K.; Manzoor, K.; Manoth, M.; Vadera, S. R.; Kumar, N.; J. Phys. Chem. Solids 2009, 70, 659.

26. Ahmed, F.; Kumar, S.; Arshi, N.; Anwar, M. S.; Koo, B. H.; Lee, C. G.; Microelectron. Eng. 2012, 89, 129.

27. Gaudon, M.; Toulemonde, O.; Demourgues, A.; Inorg. Chem. 2007, 46, 10996.

28. Vieira, D. D. C.; Cardoso, C. X.; Duran, R. M.; Quim. Nova 2009, 32, 1704.

29. Kumagai, H.; Oka, Y.; Kawaya, S.; Ohba, M.; Inoue, K.; Kurmoo, M.; Okawa, H.; Polyhedron 2003, 22, 1917.

30. Katô, H.; Akimoto, K.; J. Am. Chem. Soc. 1974, 96, 1351.

31. Obeid, M. M.; Edress, S. J.; Shukur, M. M.; Superlattices Microstruct. 2018, 122, 124.

32. Rangappa, D.; Naka, T.; Kondo, A.; Ishii, M.; Kobayashi, T.; Adschiri, T.; J. Am. Chem. Soc. 2007, 129, 36.

33. Hoang, L. H.; Hai, P. V.; Hai, N. H.; Vinh, P. V.; Chen, X.-B.; Yang, I.-S.; Mater. Lett. 2010, 64, 962.

Submitted: January 14, 2020

Published online: April 28, 2020 